\title{
The evaluation of a digital information literacy program
}

Received: October 2011

\author{
Aneé Sieberhagen ${ }^{1}$, Nampak R\&D, South Africa \\ anee.sieberhagen@za.nampak.com \\ and \\ Linda Cloete ${ }^{2}$, INFOBUZZ CC, South Africa \\ Icloete@iafrica.com
}

Accepted: September 2012

The article reports on the evaluation of a digital information literacy program (DILP) to determine the program's effectiveness in enhancing students' digital information literacy skills. The DILP was originally designed and developed for the South African student, as member of Generation $Y$, but was adapted after identifying the characteristics of Generation $Z$. This information was incorporated in the existing DILP, therefore making the DILP applicable to and useful for both Generations $Y$ and $Z$. New learning technologies were identified and incorporated in the DILP to enhance students' learning experience. An analysis of reported research indicated that there is a lack in the evaluation of programs to determine their effectiveness in enhancing the digital information literacy skills of students by using an outcomes assessment instrument. The development of an outcomes assessment instrument, which is based on internationally benchmarked information literacy competency standards and their outcomes, are presented. Evidence is provided of the effectiveness of the program in order to prove its worth as an instructional program. Recommendations are made on how digital information literacy programs may be improved to be more effective in enhancing students' digital information literacy skills.

Keywords: Program evaluation; digital information literacy; Web-based tutorials; academic libraries; outcomes assessment

\section{Introduction}

The aim of this study was to evaluate a digital information literacy program to determine the program's effectiveness in enhancing students' digital information literacy skills.

A digital information literacy program, named the DILP, was designed and developed in 2006 to enhance digital information literacy skills of students and a formative evaluation was done during the design and development of the DILP.

According to the ACRL's (Association of College and Research Libraries) Institute for Information Literacy (2011), one of the characteristics of information literacy programs

\footnotetext{
${ }^{1}$ Aneé Sieberhagen (PhD) is the Business Information Manager at Nampak R\&D, South Africa.

${ }^{2}$ Linda Cloete (D.Phil) is a Member of INFOBUZZ CC, South Africa.
} 
that illustrates best practice is the evaluation of the program itself. In his influential article, Barclay (1993) already pointed out that librarians need to evaluate library instruction programs as there is an increased demand for evaluation. Tronstad, Phillips, Garcia and Harlow (2009: 54) state that comprehensive evaluation of online information literacy programs is sparse and Walsh (2009: 19) mentions that insufficient research has been conducted on whether information literacy programs are effective. The evaluation of educational or instructional programs and products are often set aside or discarded because of other considerations and it is not unusual that such programs are not evaluated in any fashion (Sharpless Smith 2010: 177).

Library instruction programs consisting of bibliographic instruction and user education/instruction evolved in the 1990s into information and digital information literacy programs, such as the DILP (Lloyd \& Williamson 2008). The evaluation of these library instruction programs was mostly concerned with how librarians performed as teachers, what the students gained from the instruction in terms of understanding how to find information in libraries, how well students compiled bibliographies and used references in assignments as well as students' opinions of these programs (Rader 2000).

Since the ACRL produced the Information Literacy Competency Standards for Higher Education in 2000, libraries began to evaluate the effectiveness of information literacy programs in terms of students' ability to demonstrate the desired information literacy skills and knowledge after working through the programs. During the past several years (from 2000 onwards), there have been indications of assessing students' information literacy skills and outcomes assessment of information literacy programs.

A review of library literature confirmed the paucity of the evaluation of library instruction programs which includes meaningful assessment of students learning through outcomes assessment. The literature also revealed the lack of outcomes assessment instruments which are based on information literacy competency standards and those designed with proven validity and reliability.

More and more higher education institutions are incorporating information literacy programs and the need to develop evaluation methods and tools to assess their impact is therefore arising. 'Evaluation has become an extremely important topic in the field of information literacy, and it should also become a priority line of research' (GarcíaQuismondo 2010: 34).

Furthermore, a review of the literature found no evidence of the evaluation of the effectiveness of information literacy programs or digital information literacy programs which includes meaningful assessment of student learning through outcomes 
assessment in South Africa. For the above-mentioned reasons, the evaluation of the DILP was undertaken.

\section{Research procedure}

Program evaluation is one of the three types of research that utilise both quantitative and qualitative approaches (De Vos 2002: 372). By using the combined qualitative and quantitative approach, the research focused on Creswell's mixed methodology design model. This means that the research used mixed aspects of the qualitative and quantitative approaches which involved, for example, gathering both numeric information (on instruments such as the pre- and post-tests) as well as text and verbal information (e-mail and telephonic interviews) (Creswell 2003: 20).

\subsection{Research design}

A quasi-experimental design was used, more specifically, the single-group pre-test/posttest design. This was chosen as it is an improvement on the single-group post-test design, since measures are taken twice (before and after the treatment) and the two measures can then be compared to determine the result of the treatment. This type of design is also widely used in educational research (Gribbons \& Herman, 1997).

A challenge of using the single-group pre-test/post-test design was the lack of a control group, which exposes the design to threats to internal validity. These potential threats to internal validity, namely selection, mortality, instrumentation, regression, maturation, history and testing, were identified and ruled out to enable one to argue that nontreatment factors did not account for the change in participants' scores and that the treatment (the DILP) caused the effect (Mitchell \& Jolley 2007: 444-445).

When dealing with selection, the study did not use a design that involves comparing one group of participants with another, since the participants were tested against themselves.

Mortality refers to participants dropping out of the study. To control this threat, treatments were brief; it took the students approximately one and a half hours to complete the pre-test, work through the DILP and complete the post-test.

Mitchell and Jolley (2007: 447) recommend that the instrument should be administered the same way every time. To ensure this, each student first had do the pre-test, work through the program and then complete the post-test, ensuring a standardised way in which the instruments were administered. 
Regression is a potential threat if the researcher selects individuals for a group based on extreme scores, because they will naturally do better (or worse) in a post-test than the pre-test regardless of the treatment. To deal with this threat, the students were not selected but participated voluntarily.

Maturation is a treatment effect that is caused by natural biological challenges such as fatigue or hunger (Mitchell \& Jolley 2007: 445). To prevent this, the research was conducted in a short period of time - shorter than examinations usually taken by students.

History can pose a threat to internal validity when the group being studied experiences an event - unrelated to the treatment - that may be responsible for the results instead of the program itself (Martin 1997). To deal with this, the students were isolated from external events by completing the tests and working through the DILP in a laboratory assigned to the researcher for the duration of the study.

In general, taking a test affects subsequent testing. Participants' performance may differ from an initial testing, not because of the treatment, but because they are familiar with the measure (PsychoMetrics, s.a.). To deal with this threat, the researcher used similar but not identical pre- and post-tests to prevent the students from being "prepared" for the post-test by the pre-test itself.

\subsection{Population}

The study concentrated on Generation $Y$ and $Z$, therefore the population was students from Generation $Y$ and $Z$. Generation $Y$ are those people who were born between 1978 and 1990 and their ages, in 2010, range between 20 and 32 (Pierce 2007). Today's Generation Z follows right on their heels. Generation Z comprises anyone born in or after 1990 (Geck 2006). Their age, in 2010, was 20 years or younger.

Since it was impossible to involve all the Generation $Y$ and $Z$ students of the various universities, the university with the most contact students was therefore chosen. Contact students are those who are registered mainly for courses offered in contact mode. They are also more likely to fall into the age category of 32 years or younger, rather than distance and postgraduate students who may include students from older age groups.

According to the South Africa, Department of Education (2009: 33), the university with the most contact students is the Tshwane University of Technology (TUT). The size of the population was therefore $N=46570$, for all the campuses of TUT. The contact students $(N=46570)$ of TUT generally represent the characteristics and representative 
attributes of the population: they are from Generation $Y$ and $Z$ and are 32 years or younger.

\subsection{Sampling}

A sample was used as it results in more accurate information and therefore only a portion of the population was used in the research. The size of the sample was determined by using the guidelines for sampling, offered by Stoker (as quoted by Strydom 2005: 196).

The sample size was calculated at $n=931$ for all the campuses of TUT. Since the Nelspruit Distance Campus was willing to allow the researcher to make use of their resources, an attempt was made to get a sample size of $n=931$ from the approximate 1700 students on this campus. It was expected that the responses would not be a $100 \% ; 510$ students consequently took part in this study. Furthermore, the Nelspruit Distance Campus of TUT was representative of the population ( $N=46570)$, as most of the 1756 students from this campus represent the characteristics and representative attributes of the population, namely being 32 years or younger and belonging to Generation $\mathrm{Y}$ and $\mathrm{Z}$.

In sampling individuals for the research, the sampling method was also taken into consideration. Non-probability sampling took place. Non-probability sampling, according to Jackson (2009: 96), is normally used because it tends to be less expensive and it is easier to generate samples using this technique. Since this research was not concerned with balanced sample representation as in the case of surveys, the results are not generalizable.

Self-selection sampling therefore occurred as 510 students identified their desire to take part in the research after the research project was publicised on campus by the heads of the departments and lecturers who distributed information leaflets and invited students to take part in the research project.

For the qualitative approach, particular students were selected deliberately in order to provide information that could not be obtained from other persons (Maxwell 2005: 88). More specifically, criterion sampling was used, which involves the selection of all cases that meet some criterion (Patton 2002: 238) - in this instance, all the students who performed worse in the specific post-test questions after working through the DILP. They were the only students who could provide possible reasons for problems and/or misunderstandings that students could have experienced with the specific question in the outcomes assessment instrument. 
Thus, for the follow-up interviews, the researcher consciously selected certain respondents to be included in the study (Zeelie 2004: 120), based on the results from the quantitative research. The sample size depended on the number of students who failed to do better in the post-test than the pre-test, after working through the DILP. The sample size for the qualitative research was therefore $n=453$.

\section{$2.4 \quad$ Research instruments}

For the purpose of this study, questionnaires and interviews were used. The questionnaires were pre- and post-tests, used during data collection, and follow-up telephonic and e-mail interviews were also used, in cases where students performed worse in the post-test than the pre-test.

Walsh (2009) reviewed library literature in order to provide an overview of the most popular instruments and those which show how reliability and validity of the instrument have been considered, as well as those mapping to the ACRL Information Literacy Competency Standards for Higher Education (ACRL, 2000). The ACRL Information Literacy Competency Standards for Higher Education provides a framework for assessing information literacy and lists a range of outcomes for assessing student progress towards information literacy.

Walsh's (2009) research discovered that multiple-choice questionnaires are the most popular. The multiple-choice questionnaire is an instrument which is often chosen for convenience as it allows for

- Easy testing.

- Objectivity (in marking, there is usually only one correct answer).

- Ease of marking.

- Testing large groups.

- Developing items to test higher level intellectual skills (University of Technology Sydney, Institute for Interactive Media and Learning 2007).

The tests were designed to measure the learning outcomes of students in order to evaluate the effectiveness of the DILP. From the results gathered, the overall effectiveness of the DILP was inferred. The advantages of tests are that one can 
measure how much students know at the end of the program and how much improvement has been brought about by the program itself (Alessi \& Trollip 2001: 555).

Furthermore, objective tests were used. Objective tests are tests containing factual questions that can be quickly scored with an answer key, therefore minimising subjective judgements by the person taking the test and the person scoring it (Dictionary.com 2011). The pre- and post-test were scored with an answer key.

The study used a variety of creative types of assessment questions which included multiple-choice, true/false, matching and completion stems. The majority of the questions were created as selected-response items using multiple-choice and true/false. English was used for both the pre- and post-test as English is the medium of instruction at most universities, including the Tshwane University of Technology. The pre- and post-test comprised 30 questions each. A preliminary draft, which was tested on a sample of students, indicated that the tests took about 30 minutes each, on average, to be completed.

Considering the above-mentioned, it was decided to use the multiple-choice questionnaire as the preferred outcomes assessment instrument, and to design the questionnaire to be a valid and reliable outcomes assessment instrument, where the questions are mapped to the specific information literacy outcomes as set out by the Information Literacy Competency Standards of the ACRL (2000) and the Information Literacy Standards of the CAUL (Council of Australian University Librarians) (2001). Walsh $(2009: 22,25)$ states that it is obvious from the literature that producing such a questionnaire is not easy.

\subsection{Validity and reliability}

For the outcomes assessment instrument (the pre- and post-test) to be of any value, it must have shown validity and reliability (Ondrusek, Dent, Bonadie-Joseph \& Williams, 2005: 402). It was therefore important to determine the validity and reliability of the preand post-test. The following measures were taken:

- Information literacy experts from South Africa and abroad were asked to determine whether the questions in the pre- and post-test are truly mapped to the chosen ACRL and CAUL standards and their outcomes, therefore assessing the content validity.

- The pre- and post-tests are different but equivalent: they have the same number of items, the same level of difficulty and the same instructions and format, which ensure alternate-forms reliability. Alternate-forms reliability also controls 
test/re-test problems where the potential for memorisation of the test, if the exact same test is used for the pre- and post-test, is eliminated (Jackson, 2009:68).

- To gauge the reliability of the tests, the tests should be administered twice at two different points in time. Prior to administering the tests to the students it was administered to a small group of students, similar to the population of the research study, with the aim of refining the test. This step ensured test/re-test reliability, since the test is administered twice at two different points in time, namely before the actual administration of the tests and during the actual administration of the tests.

Validity and reliability of questionnaires used in the follow-up interviews were also ensured. A typical strategy for improving the validity and reliability of research and evaluation of the findings is triangulation. Triangulation strengthens the study by combining the use of multiple instruments of data collection and data analysis. For the purpose of the study, pre- and post-tests and follow-up interviews were therefore used as data collection instruments. The data were analysed, using both quantitative and qualitative data analysis (Cano 2000: n.p. \& Golafshani 2003: 604).

\subsection{Mapping to the ACRL and CAUL standards and outcomes}

Standards can be applied to assist in the identification of appropriate outcomes and to design outcomes assessment instruments. These standards refer to information literacy standards. In 2000, information literacy competency standards were created by the ACRL (2000) and still serve as the benchmark for information literacy programs.

CAUL adopted these in 2001 and added two more standards to the five standards of $A C R L$. For each standard there are listed outcomes. The various units of the DILP were written according to a combination of the ACRL and CAUL standards.

The questions for the tests were therefore written according to the outcomes as set out in the DILP which were based on the outcomes of the ACRL and CAUL.

\subsection{Interviews used as research instruments}

Telephonic and e-mail interviews were used as a second instrument. The question sheets for the follow-up interviews were created to gather the students' opinion on some of the questions in the outcomes assessment instrument as well as the DILP itself. These were the questions where the students failed to answer the post-test question correctly, but answered the pre-test question correctly. These specific questions from 
the outcomes assessment were identified after the quantitative data from the DILP testing had been analysed.

The question sheets for the follow-up interviews contained three questions. The questions were open-ended questions, asking the students to provide their answers to the questions.

\subsection{Administering the pre- and post-test}

Three steps were involved in administering the pre- and post-tests for this study. Firstly, consent and assistance were requested and obtained from the Nelspruit Distance Campus of TUT.

Secondly, a designated laboratory with Internet access was assigned to the researcher and students willing to participate in the research project arrived at a time scheduled by the students themselves. The DILP was made available in CD-ROM format and also loaded onto the computers.

Thirdly, the pre-test was handed out to the students. After the students completed the pre-test, they had to work through the DILP and then complete the post-test. Once the pre- and post-tests were completed, it was necessary for the data to be extracted and collated in some form of analysis.

\subsection{Analysis of the DILP test results}

Specific methods for testing and analysing the results from the pre- and post-test were used to suit the requirements of the study. SPSS was used to extract data from the completed Excel data entry template.

Data analysis therefore involved the following:

- running descriptive analyses to get reports on data status (descriptive statistics).

- reaching conclusions extending beyond the immediate data (inferential statistics).

The analysis of the data also assisted the researcher in identifying the questions in the pre- and post-test where two counts differed significantly and follow-up interviews were needed. 


\subsection{Telephonic and e-mail interviews - data collection}

After the quantitative data was analysed, the questions which showed a decrease which was statistically significant (with a significance level of less than $0.05[p<0.05]$ ) were pinpointed and follow-up interviews were conducted concerning each of these questions. For each question, the filtering function in Excel was used to identify the students to whom the follow-up questions had to be e-mailed or, in cases where the email address was not known, the students who had to be telephoned.

Of the 453 students identified, 249 students were contactable (available telephone numbers and e-mail addresses). The number of students is less than the original 510 since some students dropped out, others were ineligible and some of the questionnaires were rejected. Once again, the study strove to draw the largest possible sample (249), but non-responses did occur. Non-responses occurred due to respondents being located but unable to make contact or refusal to respond. Students' refusal to respond, however, supports the principle of voluntary participation. Eighty-seven (87) students responded to the questions in follow-up interviews.

A point of data saturation was reached, where no new themes emerged from the data. Therefore, there was no need to contact the students with whom the interviewer initially did not make contact.

\subsection{Analysis of the results from the follow-up interviews}

The process of analysing the qualitative data obtained from the interviews started by sorting and arranging the data from the interview sheets into an Excel spreadsheet. For each of the identified questions a new work sheet was created and the words and phrases used by the students were entered into the work sheets.

The researcher then attempted to get a general sense of the information, that is, what general ideas were expressed by the students? The detailed analysis began with a coding process. By using in vivo coding, a small number of themes were identified. The themes were then converted into a quantitative format using SPSS, which was followed by the interpretation of the data. 


\section{Discussion of the results of the study}

In this section the results and recommendations are presented.

\section{1 Characteristics of Generation $Y$ and $Z$}

The study showed that the DILP was generally effective in enhancing students' digital information literacy skills, showing that there were tangential points with the students' characteristics, such as their positive abilities with technology, preference of non-linear interaction with information, technology as motivation, learning coupled with entertainment in the form of visual and audio information, computer literacy, electronic multitasking and effortlessness with technology, which were addressed in the adaptation.

The analysis of student feedback also proved that the DILP was adapted effectively, as the students found the DILP to be enjoyable, informative, interesting and stimulating. Students also suggested that the program should be undertaken in groups. This corresponds strongly with the teamwork and peer learning characteristics of these generations.

It therefore proves the significance of designing and developing, and also adapting current digital information literacy programs, such as the DILP, by taking the intended audience's characteristics into consideration.

Recommendations: Academic libraries at higher education institutions should attempt to design and develop their digital information literacy programs or web-based information literacy instruction programs, based on their audience's characteristics to ensure the effectiveness of their programs. Academic libraries could also endeavour to establish which generations are using their library and adapt their current digital information literacy programs to address these generations' characteristics.

It would further be advisable for academic libraries to enable students to work through programs, such as the DILP, in a collaborative environment, where students can be divided into groups in laboratories and each group can work through the DILP whilst it is displayed via a data projector and also on monitors for each student. Discussions, activities and quizzes in the DILP can be completed in teams.

This is consistent with the teamwork and peer learning characteristics of these generations. Students from these generations are used to group projects and assignments and they prefer teamwork. Teamwork will furthermore result in peer learning. Peer learning is important to them because they strongly identify with others in 
their age group. Students from Generation $Y$ generally rely on their peers to learn how to use a computer, educational and instructional programs such as the DILP and various other computer applications.

The qualitative data analysis showed that students felt that they did not gain sufficient knowledge and needed more information to answer some of the questions. They would also like the program to be presented on a regular basis. This will enable students to redo the sections they do not feel comfortable with, therefore assisting them to memorise the content of the DILP. Generation $Y$ has the characteristic of unwillingness to memorise, but their positive abilities with technology might encourage them to work through the program again.

Students at institutions of higher education - especially in South Africa - have a wide range of academic experience (or lack thereof), with specific reference to computer literacy and academic preparedness. Presentation of the DILP on a regular basis may assist those students who lack academic preparedness and computer literacy in assisting them to acquire digital information literacy skills.

The program could be presented on a regular basis

- at the start of every semester.

- during information literacy instruction sessions.

- weekly, and students who could not attend a specfic session due to class attendance or other activities can then attend the sessions they have missed when it is offered again.

- through the academic libraries' home pages on a 24-hour basis.

It is a well-known fact that these generations are the most electronically connected generations and, due to the fact that they use Web browsers, cellular phones, instant messenger services and wireless connections, are constantly connected to the Internet and their friends.

The above-mentioned permits them to communicate regardless of their physical location, to access a wealth of digital information and to author or contribute content to Web sites and weblogs. It is therefore important to emphasise the availability of digital information literacy programs or information literacy web-based instruction through academic libraries' home pages on a 24 -hour basis. 
Generation Z displays the characteristic of different information seeking behaviours. This was also proved during the testing of the DILP, as they demonstrated an inability to identify a well constructed search strategy. The literature also refers to their inability to search databases effectively. This is mainly due to the fact that they start off with Google searches and merely concentrate on the highest-ranked results on the first page. They are often unaware of databases.

The testing of the DILP furthermore indicated their lack of critical-thinking skills in, for instance, evaluating digital information literacy sources. Students were able to use the date criterion to evaluate a Web site, but not the authority and content criteria. When enhancing students' digital information literacy skills, libraries should pay extra attention to the construction of effective digital search strategies and evaluation of Web sources, by including innovative sections in their digital information literacy programs.

\subsection{Identification and incorporation of new learning technologies in the DILP}

The research study also strove to determine the effectiveness of the program by incorporating new learning technologies in the DILP to make it useful to students from Generation $\mathrm{Y}$ and $\mathrm{Z}$.

The identification and incorporation of new learning technologies such as multimedia Web sites, RSS, blogs, digital storytelling, online games, social networking and e-mail in the DILP, further allow for addressing Generation $Y$ and Z's characteristics of using technology as motivation, visual orientation, electronic multitasking, constant communication and learning coupled with entertainment in the form of visual and audio information.

This proved to be effective especially in the section, Current awareness services, in Unit 7 of the DILP where RSS, blogs and Twitter are explained by means of multimedia Web sites, namely YouTube. Students proved their understanding of current awareness services by showing an improvement in the post-quiz.

To further incorporate new learning technologies in the DILP, Unit 7 links students to the DILP blog which contains digital information literacy aspects, such as multimedia on Boolean operators, to further enhance digital search strategies. There are also digital information literacy quizzes which should address the generations' preference for learning coupled with entertainment in the form of visual information. The DILP blog can be found at http://dilpstudent.blogspot.com.

Since the Web today is built around the concept of social networking, the DILP also has a page on Facebook. The fact that Generation $Y$ and $Z$ prefer constant communication 
means that they can now communicate and share information with friends on digital information literacy. The Facebook group can be found under DILP on Facebook or by using this URL: http://www.facebook.com/group.php?gid=134808366535728.

Recommendations: New emerging learning technologies were identified which can also be included in the DILP. They are:

- Chat

- Web conferencing

- Mailing lists

- Interactive animations.

With chat, students and instructors can be connected online and they can converse by typing in text that is transmitted in real-time to the other person's computer screen. Instructors and students can communicate with one another (for instructional purposes or research assistance) whilst working through the program. This will further address the characteristic of constant communication of Generation $Z$ and the importance of the mentor characteristic of Generation Y.

Web conferencing makes the usage of audio and video possible. A group of people can be connected, while they are viewing the same program, such as the DILP, and can converse about certain issues arising from working through the program, in the same manner as people are using Skype or webinars today. This would be very suitable for the teamwork, peer learning, learning coupled with entertainment in the form of visual and audio information and constant communication characteristics of Generation $Y$ and Z.

Libraries can use mailing lists to facilitate the distribution of digital information literacy course information, for example sending a unit of the DILP to students to work through. This can be done as a one-way communication tool, where instructions are sent to students enrolled to take part in the program or as a posting to all students enrolled at an institution of higher education.

Interactive animations are multimedia that can add an elaborate and engaging level of interactivity to a program. Libraries can use them to build simulations or create interactive activities to assist in teaching digital information literacy concepts. Flash and Shockwave are examples of interactive animations. 
Digital storytelling is an innovative way to introduce digital search strategies and other digital information literacy concepts and to evaluate Web sources. Digital storytelling is a short movie, containing the script of the subject to be introduced, images, video, music and narration and is about 2-10 minutes long. Academic libraries can use digital storytelling to introduce various digital information literacy concepts and include them in their online information literacy instructions.

Academic libraries should keep abreast with the latest learning technologies and digital devices to enhance students' learning experience and should also incorporate these in the DILP, should the DILP be used.

If academic libraries ensure that their web-based instructions or digital information literacy programs are applicable to the students involved and new learning technologies are incorporated with such programs, the evaluation of programs should become important.

\subsection{Evaluation of the effectiveness of the DILP}

As mentioned previously, the literature reported that insufficient research on the evaluation of the effectiveness of digital information literacy programs has been conducted in South Africa and abroad. Even more so, in terms of students' ability to demonstrate digital information literacy skills by using an outcomes assessment instrument with proven reliability and validity.

The DILP was therefore evaluated by using a valid and reliable outcomes assessment instrument. After the data analysis and interpretation were completed, the following three categories of findings were identified with reference to the different units and sections of the DILP:

- The DILP made a noticeable positive change - effective sections.

- The DILP made no noticeable change - proficient sections

- There was a noticeable negative change - sections where possible changes can be made.

Figure 1 illustrates the most effective sections, sections where possible changes can be made and proficient sections in the DILP. 
Figure 1 Most effective sections, sections where possible changes can be made and proficient sections in the DILP

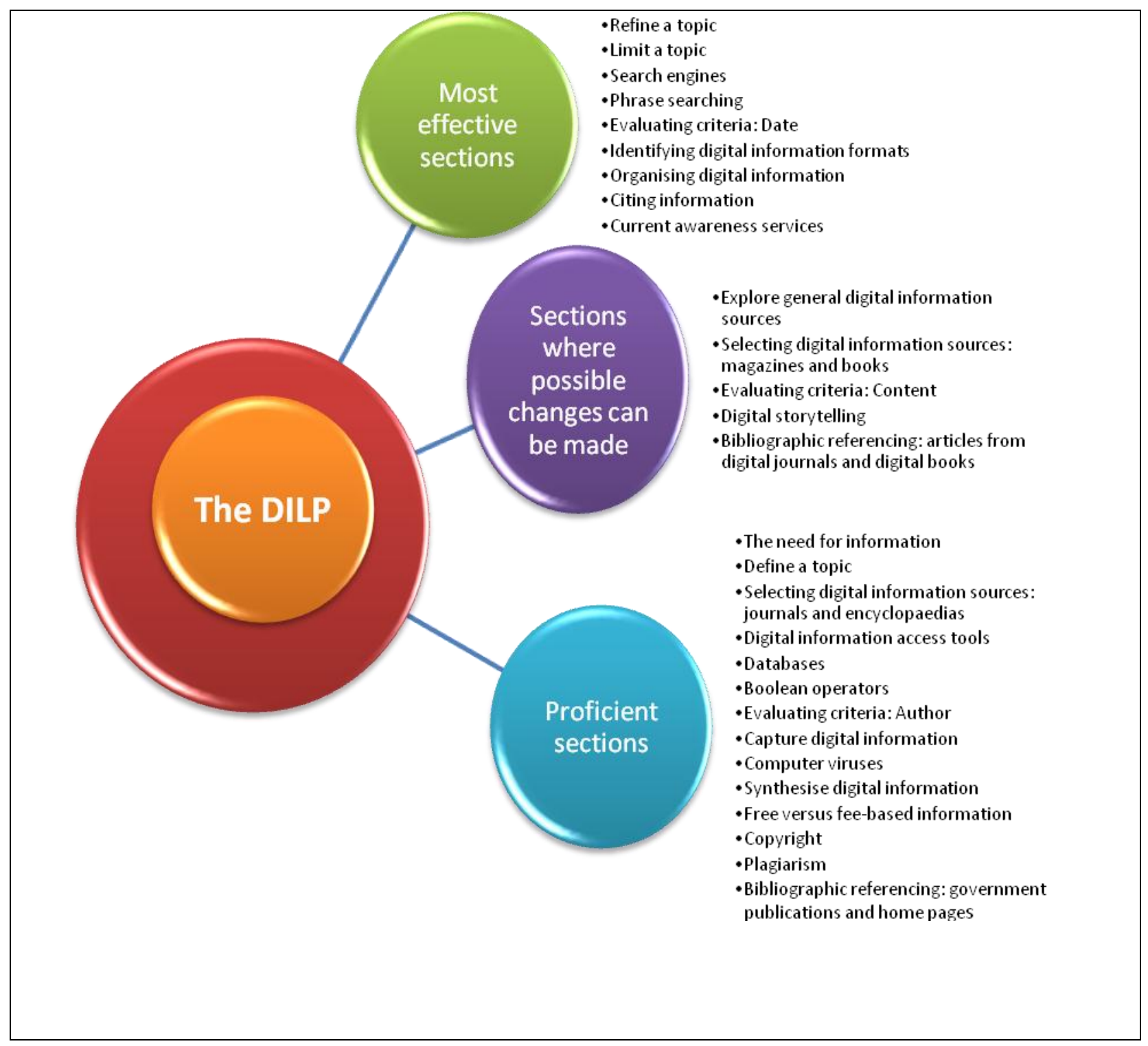

The evaluation proved that the DILP is effective in enhancing the digital information literacy skills of students.

Recommendations: Academic libraries should evaluate their digital information literacy programs or other web-based instructional programs which will allow them to judge the effectiveness of the program and, by doing so, also judge its worth as an educational and instructional program. 


\subsection{Development of the outcomes assessment instrument}

During the development of the outcomes assessment instrument, it became clear that, in general, the instruments previously used were merely standardized tests which only tested the skills of students and gave little indication of the real breadth of the assessment instrument or its validity and reliability. Another aim of the research study was thus to develop an outcomes assessment instrument with proven validity and reliability.

After the testing of the DILP and the follow-up interviews, some findings were made with regard to some of the questions in the outcomes assessment instrument. These were the questions where the students failed to answer the post-test question correctly, but answered the pre-test question correctly.

In summary, students found some of the questions, or the options provided, difficult or did not understand the question or the options provided. It is advisable that the options used in multiple-choice questions should also be discussed in Web-based tutorials to aid the memorisation characteristic of the generations. During the development of outcomes assessment instruments, one must ensure that different questions are not testing the same skill and multiple-choice questions in grid-like format should probably be avoided as students may find the layout confusing.

Recommendations: The use of alternative methods to evaluate the effectiveness of programs would be relevant and useful to investigate. Examples of these can be ePortfolios and simulations. With ePortfolios, the students can create a product or engage in activities, applying their new digital information literacy skills. The work is accumulated and stored over time to be reviewed to show their progress in acquiring digital information literacy skills.

Once again, it would be important for these methods to show how validity and reliability were ensured as well as how these methods were mapped to information literacy standards as set out by different associations, such as the ACRL or CAUL.

Another recommendation for the outcomes assessment instrument would be to develop it as a web-based assessment tool built into the instruction, with online feedback to students and the evaluator. The questions in the quizzes in the various units of the DILP can be replaced with the questions of the pre-test. When the student answers a question, it provides immediate feedback and the student can proceed to the next question. Once the student has worked through the DILP, the post-test will also be given in a web-based environment. The results can be calculated immediately without having to mark the tests manually. 


\section{Conclusion}

The value of this research is clear, as the literature indicated the paucity of the evaluation of the effectiveness of information literacy web-based tutorials, such as the DILP, which includes a meaningful assessment of student learning through outcomes assessment. There is no evidence of such evaluation undertaken in South Africa. The literature also indicated the lack of outcomes assessments which are based on benchmarked information literacy competency standards and their outcomes as well as outcomes assessment instruments designed with proven validity and reliability.

No indications could be found where programs such as the DILP were evaluated, while new learning technologies were incorporated in the program and it was designed, developed and adapted with its intended audience in mind.

This research study therefore fills the gap in this field of research, by determining the overall effectiveness of the program, as it

- incorporated new learning technologies in the DILP (informed by the characteristics of Generation $Y$ and $Z$ students), to make it useful to students from these generations.

- designed an outcomes assessment instrument based on the outcomes as set out in the benchmarked information literacy standards and outcomes of the ACRL and CAUL.

- ensured validity and reliability of the outcomes assessment instrument by applying content validity and alternate-forms reliability.

- carried out an outcomes assessment by measuring students' digital information literacy skills using the outcomes assessment instrument.

- proved that the DILP was effective in enhancing the digital information literacy skills of students, resulting in the fact that the DILP is viewed as an effective digital information literacy program that could be valuable as a web-based tutorial to enhance the digital information literacy skills of Generation $Y$ and $Z$.

Academic libraries that cannot afford the luxury of a digital information literacy expert or training/instruction librarian can still offer their students access to digital information literacy programs by making the DILP available to students via the library's home page. Higher education institutions such as traditional universities, comprehensive universities and universities of technology which do not have comprehensive digital information 
literacy programs such as the DILP can also use the DILP to offer their students digital information literacy training.

A single research study, such as this, is by nature restricted to what can be accomplished in four years' time. An important result of this study is to present a set of ideas for further research.

Based on this research, targets for additional research could be:

- The design and development of a digital information literacy program specifically for Generation Z or the "digital natives" and the evaluation thereof. The study showed an approach to the design, development and adaptation of a digital information literacy program for Generations $Y$ and $Z$ and the evaluation thereof. There are, however, opportunities for detailed research on a web-based tutorial for "digital natives".

- The development of alternative online outcomes assessment instruments for web-based tutorials with proven validity and reliability. The study indicated an approach for an outcomes assessment instrument, but there are more opportunities to develop alternative online outcomes assessment instruments.

- This study showed the results of integrating new learning technologies with the existing DILP. These results open the window for much more detailed research in the area of improving the integration of emerging learning technologies with web-based tutorials and the evaluation of their effectiveness.

The ACRL (2010 \& 2011) propounds in its Guidelines for Instruction Programs in Academic Libraries and Characteristics of Information Literacy that Illustrate Best Practices: a Guideline: Best Practices Initiative, the evaluation of instruction programs using direct measures such as assessing the overall effectiveness of programs by utilising appropriate evaluation methods such as program evaluation. The evaluation of digital information literacy programs should be an ongoing process aimed at understanding and improving instruction programs at higher education institutions.

\section{$5 \quad$ References}

ACRL (Association of College and Research Libraries). 2000. Information literacy competency standards for higher education. [Online]. Available:

http://www.ala.org/ala/mgrps/divs/acrl/standards/standards.pdf [site accessed 4

September 2012]. 
ACRL (Association of College and Research Libraries). 2010. ACRL guidelines for instruction programs in academic libraries. [Online]. Available:

http://www.ala.org/ala/mgrps/divs/acrl/standards/guidelinesinstructio.pdf [site accessed 3 September 2012].

ACRL (Association of College and Research Libraries). Institute for Information Literacy. 2011. Characteristics of programs of information literacy that illustrate best practices: a guideline: best practices initiative. [Online]. Available:

http://www.ala.org/acrl/standards/characteristics [site accessed 5 September 2012].

Alessi, S.M. \& Trollip, S.R. 2001. Multimedia for learning: methods and development. $3^{\text {rd }}$ ed. Boston: Allyn and Bacon.

Barclay, D. 1993. Evaluating library instruction: doing the best you can with what you have. $R Q, 33(2)$, Winter.

Cano, V. 2000. Reliability \& validity in qualitative research. Edinburgh: Queen Margaret University.

CAUL (Council of Australian University Librarians). 2001. Information literacy standards. $1^{\text {st }}$ ed. Canberra: Council of Australian University Librarians.

Creswell, J.W. 2003. Research design: qualitative, quantitative, and mixed method approaches. $2^{\text {nd }}$ ed. Thousand Oaks, Calif.: Sage.

De Vos, A.S. 2002. Combined quantitative and qualitative approach. In De Vos, A.S., Strydom, H., Fouché, C.B. \& Delport, C.S.L. (eds.). Research at grass roots: for the social sciences and human service professions. $2^{\text {nd }}$ ed. Pretoria: Van Schaik.

Dictionary.com. 2011. Objective test. [Online] Available:

http://dictionary.reference.com/browse/objective+test [site accessed 13 April 2011].

García-Quismondo, M.A.M. 2010. Evaluation of information literacy programmes in higher education: strategies and tools. Revista de Universidad y Sociedad del Conocimiento, 7(2):26-36.

Geck, C. 2006. The Generation Z connection: teaching information literacy to the newest net generation. [Online] Available:

http://www.redorbit.com/news/technology/397034/the_generation_z_connection_teachin g_information_literacy_to_the_newest/ [site accessed 2 September 2012]. 
Golafshani, N. 2003. Understanding reliability and validity in qualitative research. The Qualitative Report, 8(4), December:597-607. [Online] Available:

http://www.nova.edu/ssss/QR/QR8-4/golafshani.pdf [site accessed 2 September 2012].

Gribbons, B. \& Herman, J. 1997. True and quasi-experimental designs. Practical Assessment, Research \& Evaluation, 5(14). [Online] Available: http://pareonline.net [site accessed 4 February 2012].

Jackson, S.L. 2009. Research methods and statistics: a critical thinking approach. $3^{\text {rd }}$ ed. Belmont, Calif.: Wadsworth.

Lloyd, A. \& Williamson, K. 2008. Towards an understanding of information literacy in context: implications for research. Journal of Librarianship and Information Science, 40(1), March.

Martin, W. 1997. History threats to internal validity [online]. Available on the Internet at: http://www.socialresearchmethods.net (31 August 2012).

Maxwell, J.A. 2005. Qualitative research design: an interactive approach. $2^{\text {nd }}$ ed. Thousand Oaks, Calif.: Sage. (Applied Social Research Methods Series).

Mitchell, M.L. \& Jolley, J.M. 2007. Research design explained. $6^{\text {th }}$ ed. Belmont, Calif.: Thomson Wadsworth.

Ondrusek, A., Dent, V.F., Bonadie-Joseph, I. \& Williams, C. 2005. A longitudinal study of the development and evaluation of an information literacy test. Reference Services Review, 33(4):388-417.

Patton, M.Q. 2002. Qualitative research and evaluation methods. $3^{\text {rd }}$ ed. Thousand Oaks, Calif.: Sage.

Pierce, S. 2007. Gen Y myths debunked: are young employees really the slackers, whiners and praise-junkies they're made out to be?: here's what the experts have to say. [Online] Available: http://www.entrepreneur.com/article/179200 [site accessed 30 August 2012].

PsychoMetrics. s.a. Threats to internal validity [online]. Available on the Internet at: http://www.psychmet.com/id12.html (2 September 2012).

Rader, H.B. 2000. A silver anniversary: 25 years of reviewing the literature related to user education. Reference Services Review, 28(3). 
Sharpless Smith, S. 2010. Web-based instruction: a guide for libraries. $3^{\text {rd }}$ ed. Chicago: American Library Association.

South Africa. Department of Education. 2009. Education statistics in South Africa 2007. Pretoria: Department of Education.

Strydom, H. 2005. Sampling and sampling methods. In De Vos, A.S., Strydom, H., Fouché, C.B. \& Delport, C.S.L. (eds.). Research at grass roots: for the social sciences and human service professions. $3^{\text {rd }}$ ed. Pretoria: Van Schaik.

Tronstad, B., Phillips, L., Garcia, L. \& Harlow, M.A. 2009. Assessing the TIP online information literacy tutorial. Reference Services Review, 37(1):54-64.

University of Technology Sydney. Institute for Interactive Media and Learning. 2007. Multiple choice questions. [Online] Available:

http://www.iml.uts.edu.au/assessment/types/mcq/index.html [site accessed 7 January 2011].

Walsh, A. 2009. Information literacy assessment: where do we start? Journal of Librarianship and Information Science, 41(1), March:19-28.

Zeelie, S. 2004. Qualitative research. In Tshwane University of Technology. Directorate: Research and Development. Generic Research Methodology Course. Unit 1: Conducting Research. Pretoria: Tshwane University of Technology. 